\title{
Monadology and ethnography: Towards a Tardian Monadic Ethnography
}

\begin{abstract}
:
This article outlines the project of a 'monadic ethnography' based on Gabriel Tarde's monadology. Tarde's key contention is that 'everything is a society', i.e. that the world is made up of composite and relational entities of infinitesimal complexity called monads. These assemblages of heterogeneous elements engaged in relations of mutual possession constitute the object of study of 'monadic ethnography'. Their analysis, in turn, has a series of methodological and formal implications, including a transformation of concepts of scale, spatiality and temporality and the need to find representational strategies suitable for conveying the monads' dynamic qualities. A fieldwork example which discusses the making of a car part in a small workshop based in the Can Ricart factory in Barcelona is provided. Throughout the article, the idea of 'monadic ethnography' is discussed in relation to the recent rediscovery of Tarde's work, the work of Bruno Latour and Gilles Deleuze, and the socalled 'ontological turn' in the social sciences.
\end{abstract}

\section{Keywords:}

Gabriel Tarde; Monadology; Methodology; Ontology; Actor-Network Theory

Isaac Marrero-Guillamón is Lecturer in Anthropology at Goldsmiths, University of London. His recent work has focused on processes of urban renewal in Barcelona and London and the configuration of spaces of dissent through activism and artistic practice.

\section{Contact details:}

i.marrero@gold.ac.uk

Department of Anthropology

Goldsmiths, University of London

New Cross

London SE14 6NW

\section{Acknowledgements}

I would like to thank Theo Lorenc for his generous comments on this article, and more generally for his long-term availability to discuss all things Gabriel Tarde. Melissa Fernández read the first draft closely and provided numerous useful insights. I would also like to thank the three anonymous reviewers for their careful and critical examination of my argument - it is now, I hope, a whole lot more coherent. Last but not least, I wish to dedicate this article to the memory of Vicente, whose own version of monadology inspired this text and who, sadly, is no longer with us. 


\section{Monadology and ethnography: Towards a Tardian Monadic Ethnography}

The restoration of sociologist, criminologist, social psychologist and judge Gabriel Tarde (1843-1904) to the pantheon of social theory seems to be steadily under way. Almost forgotten after succumbing to Émile Durkheim as the leading figure of French sociology, his work has recently enjoyed a remarkable comeback. Very little attention had been paid to Tarde's work until the French re-edition, from 1999 onwards, of most of his work under the direction of Éric Alliez. Since then, Tarde has been praised by Bruno Latour $(2002 ; 2005)$ as the precursor to Actor-Network-Theory; taken up by Maurizio Lazzarato (2004) as the foundation for a new politics of multiplicity; his great controversy with Durkheim reconstructed (Viana Vargas et al., 2008) and even re-enacted; ${ }^{1}$ and his work been the subject of at least one conference ${ }^{2}$, special issues in various academic journals ${ }^{3}$, and an edited book (Candea, 2010a).

The recent translation into English of Tarde's 1895 masterpiece Monadologie et Sociologie (Tarde, 2012), 'the most metaphysical of the works of the most philosophical of sociologists' (Alliez, 1999; cited in Lorenc, 2012), adds an important piece to this revival. Tarde's monadology - which radically reconfigures the Leibnizian ontology it is based upon - is arguably one of his most remarkable theoretical contributions. The aim of this article is to explore its far-reaching implications for the conceptualisation and study of the social, and to relate those to the practice of ethnographic research.

The article is organised as follows: in the next section, Gabriel Tarde's rediscovery and some of his key ideas will be briefly discussed. Then, his monadology will be presented in some detail. This is followed by an ethnographic interlude, which will be used in turn to inform the 'monadic ethnography' proposal developed in the following section. The article 
concludes with a wider consideration of Tarde's interest for ethnography in relation to recent debates around a so-called 'ontological turn' in the social sciences.

\section{Rediscovering Gabriel Tarde}

A good part of the recent literature on Tarde revisits his intellectual dispute with Émile Durkheim over the nature and scope of sociology (e.g. Alliez, 2004; Candea, 2010a; Latour, 2002; 2005; Mucchielli, 2000; Viana Vargas, 1998). It was, we are told, a foundational moment for the discipline. Durkheim's victory would not only explain sociology's becoming over the $20^{\text {th }}$ century, but also the strangeness that reading Tarde produces today and his near disappearance from the history of social theory. For those who sympathise with his arguments, Tarde represents the path not taken, and going back to his work the possibility of plotting a line of flight from sociology (and indeed the social sciences) as we know it today (Candea, 2010b). This new wave of interest in Tarde has proved fruitful in reactivating several of his intellectual endeavours, including a statistics of the fluctuations of belief and desire (Barry, 2010; Didier, 2010); an 'economic psychology' or 'science of passionate interests' (Latour and Lépinay, 2009); the theorisation of 'contagion' and 'virality' in relation to media (Sampson, 2012); or a monadic 'sociology of associations' (Latour, 2005; Latour et al. 2012). In this article, I will avoid the controversy with Durkheim, already well discussed in the literature cited above, and focus instead on Tarde's monadology, as seen from an ethnographer's point of view. In doing this, I wish to continue a line of work advanced by Matei Candea (2010b) and Eduardo Viana Vargas (2010), who already identified the specific potential of Tarde's monadological hypothesis for ethnographic research. More broadly, the 'monadic ethnography' proposal outlined in this article is closely related to assemblage theory and actor-network theory (ANT hereafter), which is the reason why I want to engage in a partial introduction to the work of Tarde via Deleuze and Latour. ${ }^{4}$ 
In 1968 Gilles Deleuze published Différence et Répétition - a book whose title already indicates an unequivocal Tardian filiation. In a long footnote, he praises Tarde's work and concludes: 'All of Tarde's philosophy may be presented... as a dialectic of difference and repetition which founds the possibility of a microsociology upon a whole cosmology' (Deleuze, 1994: 314). There are two focal points of interest here. The first relates to Tarde's thesis that repetition, adaptation and opposition are - in that order - the fundamental dynamics that govern all phenomena (Tarde, 2000). In the case of human societies, he argued that this triad took the specific form of imitation-innovation-opposition, the idea being that it is through and by repetition (imitation) that difference is produced and distributed (as either innovations or oppositions):

...it is because certain social phenomena, such as a dogma, phrase, scientific principle, moral maxim, prayer, industrial process, or the like, tend to spread in a geometrical ratio by imitative repetition, that they interfere with one another in a felicitous or infelicitous manner. That is, the discordant sides of their nature come together in certain minds, giving rise to logical or teleological duels, which constitute first germs of social oppositions (wars, competitions, and polemics); while the harmonious sides of their nature come together in the mind of the genius, or sometimes even in the ordinary mind, producing true logical syntheses, inventions, and fruitful originations, which are the source of all social adaptation. (Tarde, 2000: 63-64)

The quote above - apart from a fitting introduction to Tarde's peculiar writing style - hints at Tarde's 'infinitesimal' or 'molecular' approach, the second focal point of interest for Deleuze, further developed with Félix Guattari in A Thousand Plateaus. Tarde's analyses insist in tracing those imitations, oppositions and innovations back to their origin in the infinitely small, where the key to the big and regular lies. As he put it: '...instead of thus explaining lesser facts by greater, and the part by the whole, I explain collective resemblances of the whole by the massing together of minute elementary acts - the greater by the lesser and the 
whole by the part' (2000: 35). Deleuze and Guattari crucially argued that this form of 'microsociology' was not, as Durkheim claimed, devoted to the individual, but to 'flows' or 'waves' instead:

Imitation is the propagation of a flow; opposition is binarization, the making binary of flows; invention is a conjugation or connection of different flows. What, according to Tarde, is a flow? It is belief or desire (the two aspects of every assemblage)... [In] the "molecular" realm of beliefs and desires... the distinction between the social and the individual loses all meaning since flows are neither attributable to individuals nor overcodable by collective signifiers. (Deleuze and Guattari, 1989: 241, emphasis in original).

I will come back to the issue of 'belief' and 'desire' and the individual/collective dualism below, in relation to Tarde's monadology. But before doing so, I will end this section with a brief introduction to Bruno Latour's engagement with Tarde.

In a series of key texts $(2002 ; 2005 ; 2010 ; 2012)$, Latour has reclaimed Tarde as a precursor to ANT, on the grounds that he had anticipated - by almost 100 years - the idea of a 'sociology of association':

[Tarde] vigorously maintained that the social was not a special domain of reality but a principle of connections; that there was no reason to separate "the social" from other associations like biological organisms or even atoms... Above all, he considered the social as a circulating fluid that should be followed by new methods and not a specific type of organism. (Latour, 2005: 13)

Because of this general principle of society as association, Tarde's sociology ignored the nature/society divide as well as the micro/macro distinction - two of ANT's most important contributions to social theory. Regarding the former, Tarde argued that society is a universal form of association, shared between human and non-human entities, and hence highlighted the inadequacy of starting from a divide between natural and social facts $a$ la Durkheim. With 
regards to the micro/macro distinction, Tarde's relational and infinitesimal approach invalidates it to a large extent, in the sense that the 'small' reveals itself to be richer and more complex than the 'big', which in fact is a mere 'extension' of some of its components (Latour, 2002). I will now turn to Tarde's monadology, where these counterintuitive positions are explained in detail.

\section{Gabriel Tarde's monadology}

'The monads, children of Leibniz, have come a long way since their birth' (Tarde, 2012: 5). Monadology and Sociology's (hereafter MS) first sentence already introduces an important caveat: these monads are rather different from Leibniz's. The term monad, from the Greek monas, a 'unit' or a 'one', has a long tradition in philosophical writings, dating back to the Pythagoreans, but it was Leibniz who popularised it in the early 1700 s. In the modern sense it is used to describe: '(1) a simple, irreducible, and sometimes indestructible entity; and (2) the minimal unity into which the cosmos and all composite things in it can be resolved; yet (3) containing within itself, in contrast to material atoms, powers and relations of which it is itself the source' (Loemker, 2006: 324). Traditionally, a monadology is a 'metaphysical system that interprets the world as a harmonious unity encompassing a plurality of such selfdetermining simple entities' (Loemker, 2006: 324). In other words, classic monadologies entail a theory of cosmic harmony, based on the coordination of a multiplicity of monads, themselves considered active substances. In Leibniz, monads are differentiated and differentiating, but also closed ('monads have no windows', as he famously put it [1898: 219]) and subject to a higher principle of harmony ensured by the existence of the supreme Monad, or God (see Viana Vargas, 1998).

Tarde's monadology departs from this philosophical tradition in key ways. It is, first of all, secular; there is no God and no pre-determined harmony. It is, also, an open and 
infinitesimal system, where monads affect each other and are themselves composite entities. $M S$ 's central hypothesis (p. 28) is that 'everything is a society, that every phenomenon is a social fact': from cells to stars, both living things and inorganic beings, they are all societies where 'social' and 'society' refer, as Latour indicated, to a form of association rather than any particular entity. It is worth examining how he arrives at this remarkable inversion of both Spencer's 'society as organism' thesis (1906) and Durkheim's first rule of the sociological method, 'to consider social facts as things' (1982). First, Tarde argues that reality is made out of monads, which, contrary to Leibniz, are not the simple elements that make up aggregates, but composite entities themselves. Drawing from findings in physics, cellular theory and chemistry, he argues that science has repeatedly shown how so-called individual bodies (e.g. planets, cells, parasites) were in fact 'a multiplicity of distinct elements linked to each other in the same way as they are linked to the elements of other aggregates' $(M S, 6)$. It is only because we look at things from a distance and they are unknown to us that we believe them to be 'indistinct, undifferentiated, and homogenous... But everywhere where a scientist digs beneath the indistinction which is apparent to us, he discovers an unexpected treasury of distinctions' (MS: 24). The progress of science, he says, continues to break more and more of these indivisible bodies into 'highly complex constructions, furnished with a specific architecture and animated by highly varied internal movements' $(M S: 9)$. In fact, it is in the infinitely small where increasing complexity is found and where actions originate, 'emanating from a multitude of agents who are so many invisible and innumerable little gods' (MS: 25) (Tarde also calls them 'hidden workers'). We know this, Tarde argues, because we can extrapolate what we know from being able to observe human society from within:

If we look at the social world, the only one known to us from the inside, we see agents, men, much more differentiated and more sharply characterized as individuals, and richer in continual variations, 
than are the mechanisms of government or the systems of laws or of beliefs, or even dictionaries or grammars, and this differentiation is maintained by their competition. A historical fact is simpler and clearer than the states of mind of any of its actors. (MS: 37$)$

The example above points at two essential characteristic of 'monads' or 'societies': first, that difference (or heterogeneity), and not identity (or homogeneity), is at their core (Viana Vargas, 2010); second, that because these entities are the result of the relations between their components or, more exactly, a provisional reflection of the hegemony of some of them over others, they are unstable. Tarde talks about the 'internal revolts' that break apart 'all great regular mechanisms', provoked by the fact that

their constitutive elements, the soldiers of these diverse regiments, the temporary incarnation of their laws, always belong only by one aspect of their being to the world they constitute, and by other aspects escape it... The attributes which each element possesses in virtue of its incorporation into its regiment do not form the whole of its nature; it has other tendencies and other instincts which come to it from its other regimentations; and, moreover... still others which come to it from its basic nature, from itself, from its own fundamental substance which is the basis of its struggle against the collective power of which it forms a part. (MS: 47)

This sense of internal agitation and instability is linked to the basic drive of monads: they are powerless in isolation, so they tend to associate; they are endowed with belief and desire, so they aim to conquer and possess other monads:

Each monad draws the world to itself, and thus has a better grasp of itself. Of course, they are parts of each other, but they can belong to each other to a greater or lesser extent, and each aspires to the highest degree of possession; whence their gradual concentration; and besides, they can belong to each other in a thousand different ways, and each aspires to learn new ways to appropriate its peers. Hence their transformations. They transform in order to conquer; but, since none will ever submit to another 
except out of self-interest, none can fully accomplish its ambitious dream, and the sovereign monad is exploited by its vassal monads, even as it makes use of them. (MS: 57-8).

Like unsettled particles in search of a companion, monads are 'bundles of possessive agencies' eager to possess each other, objects of 'reciprocal desires and beliefs' (Debaise, 2008). And this mutual possession, the very definition of society for Tarde, does not tend towards a pre-established harmony à la Leibniz; it remains a continuous movement of shifting hegemonies and possessions.

Relations of 'possession' or 'having' are indeed more fundamental and offer a much more promising footing for social theory than the old philosophy of 'being', says Tarde. Being is a crude measure of existence: it cannot be quantified, it is folded upon itself. Possession, on the other hand, reinforces the priority of relations in the constitution of reality and, as the fundamental drive of monads, is universally applicable. As he puts it in an oftenquoted passage:

All philosophy hitherto has been based on the verb Be, the definition of which was the philosopher's stone, which all sought to discover. We may affirm that, if it had been based on the verb Have, many sterile debates and fruitless intellectual exertions would have been avoided. From this principle, I am, all the subtlety in the world has not made it possible to deduce any existence other than my own: hence the negation of external reality. If, however, the postulate I have is posited as the fundamental fact, both that which has and that which is had are given inseparably at once. (MS: 52).

I will come back to the implications for ethnography of this conceptualisation of monads as unstable and heterogeneous assemblages of infinitesimal complexity defined by their relations of possession. But first, let me provide some empirical material to inform the discussion. 


\section{The Black Cap}

This ethnographic interlude is taken from a study of the conflict surrounding the eviction and demolition of the Can Ricart factory in Barcelona, approved by the City Council as part of a rezoning plan affecting the city's industrial district (Poblenou). I conducted fieldwork between 2005 and 2007, a period in which, among other things, a wide alliance to save the factory was formed, evictions were resisted and alternative plans produced, negotiations with the Council were held, most workshops ended up being displaced, and part of the factory was listed as industrial heritage. The following situation took place in June 2005, when most of the businesses still had not left the factory and were indeed resisting eviction orders and trying to negotiate better compensation payments. ${ }^{5}$

Daniel Iracheta founded his precision machining company in the 1950s. He started in Mariano Aguiló Street, in the Poblenou neighbourhood, and when business grew he moved into a bigger workshop in San Joan de Malta Street. He had to move again in 1974, because of the City Council's plans to extend the Diagonal Avenue, which however took twenty-five years to complete. He found a suitable space in Can Ricart, which had by then been divided into several workshops. Seven-hundred square meters, said Vicente, enough for his forty machines and workers. The dog, which had been barking all along, finally stopped as I paid him some attention. Vicente's office sat above the shop floor, and through the window one could see and hear the workers and the machines downstairs.

Daniel Iracheta died in 1995, aged seventy-one, and the company, now managed by his wife Emilia, changed its name to Iracheta Ltd. This had huge implications for the current situation, Vicente continued, because the landlord didn't accept the continuity of the previous indefinite lease and made them sign a new five-year contract, which had by now expired and was renewed on a monthly basis. Compensation payments were based on the length of the 
contract, so they were not only facing eviction, but the possibility of having to close. They needed about 50 million pesetas to move to a new location, and had only been offered eight million. I'm not an actual employee, Vicente clarified, but I've been helping out with the accounting since my father-in-law died and my mother took charge. I used to work in a bank, so I know about these things. I retired a few years ago. My daughter does work for the company, he said, as Belén came in and briefly joined the conversation.

The relationship with The Car Company had profoundly shaped Iracheta since they had started working for them in the seventies. From the layout of the workshop to the accounting practices, everything had been adapted to the manufacturer's requirements and protocols. In fact, in 1990 they were awarded the Y9 Quality Status certification, which recognized their excellence as suppliers and would soon be a requirement to work for The Car Company. Vicente pointed at the wall, where the certificate hung. It's a Total Quality Management system, said Belén, it covers everything since you pick up the phone until the part is delivered. We've got a Quality Manual which specifies all the processes: making a budget, ordering materials, storing parts, packing things for delivery... It allows you to prove that the part has been produced as you are supposed to. There is a record of everything we do: the measurements that were taken from the sample for quality control, the data generated by the statistical software where you introduce them, the certificates of treatment and painting, and so on. And not only with respect to manufacturing, said Vicente, there are requirements about minimum stock (for example to prevent disruptions in case of a strike), and a storage and labelling system that allowed inspectors to come and check the production without even asking.

Down in the shop floor Vicente and Belén showed me the different machine-tools, the storage area and some of the parts they made. Among them was a small black cap, the last part they made for The Car Company. It covers the screw of the rear window handle in the 
Model Qiu, he said. It's a hinged window, the glass doesn't go up and down, but instead has a lever mechanism to push it out. Already the old Model Alegria used that part. We have been making it for twenty-five years now, exclusively for the whole world. It may not look like it, but it is a very complicated process, Vicente told me with a smile. I invited him to continue. The raw material, a $0.50 \mathrm{~mm}$ thick metal sheet, comes from The Northern Foundry. Following the technical specifications of The Car Company, it has to be custom-made using a special alloy. Engineers, he said, don't think how much money they would save if they followed standards. The Northern Foundry is a big company, the minimum order they take is 20,000 kilograms. The sheet comes in rolls of 2,000 meters, which are loaded into the machine. First, the progressive stamping press cuts a circular shape, leaving two small tips; it then squashes it, constipates the bottom, and finally cuts the two tips that held the piece. It all happens continuously, do you know what I mean? Pum-pum-pum. We used to have one of those presses, but it is like anything, you have to be an expert to get it right. My father-in-law was a mechanic, and the progressive presses are for professionals. But he wouldn't have got the job if he didn't have the press, so he, a gutsy person, just bought one. He later realised he couldn't master the process, so he asked other nearby workshops to do it for him. It had to be done very precisely, it took him some time to find someone who could actually make it properly. He finally gave the job to some guy called Fernández, who had two fine presses and was also based in the neighbourhood.

But I have to tell you something, he continued, the part bears little resemblance with the original drawing by The Car Company. I mean, the cap is still a cap, but the angles, the radii and all these things are quite different. The stuff they drew could not be manufactured. Vicente laughed. Sure, they may be good drawings, but they're impossible to make, especially at the price they want to. The cap was supposed to be more rounded, but with those measures there was no way to attach it to the screw. It just couldn't be hammered onto it. Or 
maybe it could, but then the press would need sixteen operations instead of four, and this would mean making the part a lot more expensive. So we had to modify the angle, make it more open, because a sharp edge generates resistance. The engineers at The Car Company never wanted to admit it, that's just how they are, but hey, it's the only way the cap can be assembled.

There was this time when their manager was on sick leave and we were told by his substitute to make the caps properly. When the old manager later came back and saw the parts, he went What the hell have you done? They'll be returned! And indeed they were. So we had to make them badly again. He even showed us all the paperwork and said that nobody had ever ok'd the changes, but everyone turned a blind eye because they knew that was the only way to get them done at that price.

Once machined, Vicente continued, we take the parts to thermal treatment to increase their resistance. They have to be tempered, they need to be springy so that you can hammer them onto the screw later on. Once tempered, the parts have to be stripped off the husk of the treatment, otherwise the paint won't stick. The painting by the way is done in Alicante by cataphoresis. First, they give the parts a degreasing bath, to remove the oil from the previous processes and make sure they are perfectly clean. Then they are placed in racks that are immersed in the electrocoating bath, which works electrically and takes the exact amount of paint for each piece, microns. This is done by girls, said Vicente, because they have skinny fingers and are faster putting the parts in the rack. Once painted, the parts are brought here and we take them to a polyester treatment. This is expensive, because you have to put the parts one by one in another rack and spray-paint them. It also has to be the exact amount of paint. The cataphoresis and the polyester should add between 70 and 100 microns. It can't be more than that or the piece won't fit later on. 
There was once a purchasing manager at The Car Company who said from now on electrocoating only, to save costs. You can't see the polyester treatment, and all the interior black metal parts look good with the cataphoresis paint only, so she thought it was worth trying. But these caps are external parts, and the sun eats them and they rust. So we went back to the polyester treatment. In fact, in the beginning, at the time of the first Model Alegria, they were chromium-plated. But that was too expensive, it cost more than 40 pesetas per piece. That's when they decided for cataphoresis plus polyester. Now they cost about 25 pesetas. But our share is minimal, he said, 1.20 pesetas, the same as the raw material; electrocoating plus transport to Alicante cost about 6 or 7 pesetas, polyester treatment $12 \ldots$ Vincent laughed. Yes, yes, I know, it's a very laborious process, totally irrational. Other manufacturers, like Peugeot, have a much simpler system, a single piece of plastic with the cap already included in the hinge, and an inside screw. But you know what happens? That in these large companies is very difficult to change things. No one dares.

We used to supply the caps directly to The Car Company, because we had the Y9 certification. But it all changed in the eighties. If a car had say 50,000 parts, they probably had 20,000 providers. And managing that was crazy, Purchasing Managers and Departments everywhere. So at some point they decided they weren't going to buy parts anymore, but entire assembled components instead. They reduced the number of providers by a factor of 20 and also asked them to demand their subcontractors the Y9 or ISO9000 certification. I think this was pioneered by Super López, the guy who left General Motors for Volkswagen, remember him? So, anyway, we stopped supplying the cap directly to The Car Company and started selling it instead to Peninsula Glassware, which were assembling the windows. The Car Company basically forced them to buy the part from us. Thing is, Peninsula Glassware was later bought by a French multinational, Saint-Germain, and I remember the new people at quality control were reluctant to accept the caps at first, because they didn't correspond to 
the original drawings. We had to explain to them that that was the way they had to be and that we were not going to change it. In fact, they never wanted the cap in the first place, because it is hammered onto a metal screw which has the exact diameter of the window hole, and sometimes the glass breaks when assembling it. They wanted the whole part to be made of plastic, like the Peugeot one, because if you force a plastic screw against the window hole, you scrape the plastic instead of breaking the glass. It's even more airtight. But The Car Company has never wanted to change it, maybe because the Model Qiu is supposed to be discontinued soon. In fact, when we still sold the cap directly to them, my father-in-law had to make special nylon hammers for them, so they didn't crush the caps when hammering them onto the screw. He even put a magnet inside the hammers, so the workers could grab the caps more easily. Vicente nodded his head.

It was lunchtime and the workers were leaving the workshop. Most of them would go home during the two-hour break. Belén joined us again. There are fewer and fewer businesses that want to work for the car industry these days, she said. It's very competitive, too competitive. Prices go up, expenses go up, but they still force you to be $5 \%$ cheaper each year. Do what you need to do, they say, you already know the part you're making. So each year we have to somehow sort it out... We used to make fifteen parts for them, and now we only do this one. It's because of that; as time goes by you lose your profit margin.

You know what happens?, interrupted Vicente, you have to make a lot of parts to compensate for the yearly discount. You start with a good price, but after three or four years you are just breaking even on it. And after another three years you're losing money on it. But if you make more parts, and invoice for say 500 million pesetas and manage to make a 10\% or $5 \%$ profit, then that's fine. You lose money on some, and make money on others, but overall you are still making a profit. Of course, this is a cheap and convenient system for them: they know they are paying a fair price on 25 to $30 \%$ of the parts; and they also know 
you are barely breaking even on $30 \%$ of the parts and losing money on the rest. But they have managed to lower the total price by $20 \%$. If you only make a few parts you just can't make it. This is what happened to us, and that's why my father-in-law eventually stopped manufacturing the other parts for them. They didn't like that at the headquarters in Germany, and they wanted to stop all trade with us. But of course, the cap is basically our design. I mean, we're the ones who have the original drawings, not of the part itself, which at the end of the day it's their design, but the ones for the stamping press. They could draw them again, but it would cost them a lot. And since the Model Qiu is, so to speak, an endangered species, it's not worth it.

I looked again at the black cap, only a couple of centimetres of size and a few grams of weight, before heading to the canteen.

\section{Towards a monadic ethnography I: object}

In this section the proposal for a 'monadic ethnography' will be outlined, drawing both from the theoretical discussion and the example presented above. My aim is to explore what it would mean for ethnographic research to take as its starting point Tarde's monadology, that is, how his 'pansocial' (Lorenc, 2012) ontological hypothesis - 'everything is a society' may be translated into methodological strategies for doing ethnography. As it will become apparent, 'monadic ethnography' adopts and combines Deleuzian and Latournian appropriations of Tarde's work.

Researching monads means, first of all, that our objects of study are better understood as relational assemblages or entanglements. That is, as 'constellations of singularities' (Deleuze and Guattari, 1987), multiplicities made up of heterogeneous parts in relation. This in turn means that, if interrogated with sufficient sensitivity, elements are also 
likely to reveal themselves as composite entities ad infinitum. In other words, every monad is, potentially, a monad of monads. This explains Tarde's 'infinitesimal' approach to sociology, understood as a descent into the 'small', which is more complex - and indeed explains - the 'big'. As Latour et al. have put it commenting on this issue, Tarde's hypothesis is that 'there is more complexity in the elements than in the aggregates, or stated a bit more provocatively that "The whole is always smaller than its parts"' (Latour et al., 2012: 2; see also Kwa, 2002; Law, 2004). This is an image I find useful to the extent that it conveys a sense of the monads' counterintuitive internal architecture. But as explained above, Tarde's monadology is a system of open relations where monads relate to other monads and where, at least in principle, everything could be connected to everything. This means that in addition to consisting of a multiplicity of parts, monads are also likely to be part of larger multiplicities ${ }^{6}$. Therefore, what we identify as a monad at each stage of our analyses is to a large extent an effect of our position and perspective with regards to the relational web we are tapping into.

The story of the black cap provides a good example of this. First, the cap can only be understood through the association of workers, machines, production protocols, clients, raw materials, transport networks, etc. If inspected closely, it would not be hard to see in each of those entities monads-within-the-monad: the technical drawings, the production instructions, the contracts and the suppliers could all become entanglements in themselves, subject to the same dynamic of heterogeneity, coordination and instability as the car part itself. Moreover, in exploring the connections that shaped the black cap, such disparate processes as Barcelona's renewal plans, new industrial groupings in France and changes in the supply chain for a certain car company based in Germany became entangled.

Importantly, the relations and connections between and within monads are modulated by their basic drive, their 'avidity'. This 'eagerness' means that monads engage in a constant dynamic of mutual possession: they will try to conquer or assimilate other monads, 
and will in turn be approached and taken by others. Their desire for hegemony will sooner or later be met by another monad's competing avidity, resulting in a never-ending process of coupling and decoupling and a permanent battle for hegemony. Using more contemporary terms, there is no escape from relations of power in the study of monads, understood as a circulation rather than a location ${ }^{7}$. Monads are unstable arrangements, not so much in the sense of being permanently at risk of falling apart, but in the sense that their crystallisation at any given time is the result of a provisional equilibrium between forces. Vicente and Belén's narrative provided clear evidence of how power modulated the relations between the parts: the German headquarters, for instance, exerted an increasing hegemony by reshuffling the supply chain at one point, demanding the ISO9000 standard, and in the form of a 5\% annual discount rate. Rather than a metaphysics of cosmic harmony in the vein of classic monadologies, Tarde's neo-monadology is an ontology of universal struggle.

The above remarks suggest that doing monadic ethnography consists, to a large extent, in delving into this potentially infinite unfolding of relations and new monads, and charting a path through their avidity, mutual possession, and struggle for hegemony. Monads are bottomless, chasmic; monadic ethnography an abyssal endeavour. ${ }^{8}$

The monads' characteristics also suggest the need to deploy a diachronic form of analysis to fully grasp them. In relation to this, Georgina Born has convincingly argued about the need to incorporate Tarde's theory of imitation-opposition-innovation in the discussion of his monadology, noting that his method is concerned with 'analysing not only the elementary structures of process..., but their cumulative outcome in historical trajectories of variation or transformation, stability or stasis' (2010: 235).

The black cap, for example, revealed itself to be a continuous variation whose stability can only be described as a synchronic fiction. The part was a constant succession of transformations in the association between materials, providers, procedures, etc. 
Collaboration as well as competition between monads (or 'adaptation' and 'opposition' in Tarde's terms) animated these transformations: the client demanded a lower price, the glass factory lobbied for a change in materials, the manufacturer adapted the design to the budget... And yet, the part did not become something else altogether (see Law 2002). Accounting for its endurance is just as important as accounting for its continuous change. In fact, the story of the black cap is a remarkable tale of resilience (in the form among other things of several 're-alignments' of the parties involved) on the face of the radical transformations brought about by the vertical integration of European car manufacturing. The Tardian monad is a highly appropriate concept to describe this combination of variation and obduracy. ${ }^{9}$

Born further argues that the study of monads indeed requires 'an expanded analytics of temporalities' that goes beyond the 'monotemporality of becoming, which can flatten out and pre-empt investigation of the multiplicity of time' (Born, 2010: 243). The idea here is that monads are made of heterogenous temporal relations, trajectories, and rates of change. In other words, monads are palimpsestic, an amalgam of temporal sediments; doing monadic ethnography calls for an investigation of their traces, the equivalent of a geological crosssection. ${ }^{10}$ The black cap, for example, was traversed by the multiplicity of temporalities enacted by its different parts: the long duration of the materials, the shorter duration of quality standards and machine tools; the high rate of change within transport networks and the (relative) stability of the workforce... These different temporal trajectories and histories of change left some traces, which ethnographic fieldwork revealed.

This immanent conceptualisation of time has a parallel in the way that monadology approaches space. Rather than situating monads in a pre-existing and fixed Euclidian matrix, it is perhaps more appropriate to study how monads enact their own conditions of spatial im/possibility (this is an argument well-articulated in ANT: see Law, 2002: 92; Latour, 2005). 
Instead of a stable geography of scales and its concomitant vocabulary of micro and macro, local and global, monadology relies on a topology of connections and intensity, in which spatial arrangements are performed and achieved. The black cap tale was not about local processes affected by global dynamics, but about the enactment of a set of relations that produced a given spatial arrangement. In other words, the 'post-Fordist' restructuring of the car industry was not above and afar, but rather a concrete and localised wave of changes within the relational organisation of the production.

\section{Towards a monadic ethnography II: form}

This brief account of how neo-monadology transforms our objects of study already suggests the basic shape of an ethnographic approach towards them. In effect, the research of Tardian monads implies a certain monadisation of their research. Questions of form are, then, central to the debate. Monadic ethnography relies on formal strategies that can adequately convey the transformation of its object of study outlined above. ${ }^{11}$

One of the defining characteristics of ethnography, at least in its classic sense, is that it operates from within the society, group or setting it studies and through interaction with its actors. Monadic ethnography also relies on being conducted from the inside - it is only through relations that we can study relations, as Strathern and others have argued. Moreover, it is only from within that we can overcome the illusion of perfectly stable and finished entities and start to discern their immense internal complexity and agitation. Studying monads from within is therefore an active rejection of the 'view from above' (or 'nowhere'), that is, an external, superior, detached perspective (see Haraway, 1988). Monadic ethnography is about looking at the world from the monad's point of view - or, as Viveiros de Castro (2003) would put it, seeing the world the monad sees. Latour et al. have argued 
along the same lines that monads are 'a point of view on all the other entities taken severally and not as a totality... The "whole world", as Leibniz said, would be "grasped" or "reflected" through this idiosyncratic point of view' (Latour et al., 2012: 7). This is an important issue I will come back to in the conclusion. Tarde's monadology implies a multiplicity of possible points of view; consequently, discovering and adopting such perspectives is part of the monadic ethnographer's job.

Again, the story of the black cap can help us advance in the discussion. I constructed the text as a non-verbatim conversation for three reasons. First, it was a way of letting Vicente and Belén's understanding and description of the production of the car part drive the narrative - instead of mine, or any external point of view. The 'dialogic' (Bakhtin, 1981) form adopted, inspired by Peter Weiss' The Aesthetics of Resistance ${ }^{12}$ (2005), was an experiment in removing all (academic) commentary and taking seriously the way the informants told the story and performed the theoretical work themselves and in their own vernacular. The absence of a second-level, 'authorised' voice that clarifies, ratifies, explains, etc. was my way of recognising that the extraordinary story of the black cap, with all its monadic quality, belonged to them; it was their 'theory'. It took me a while to recognise that there was a remarkable isomorphism at play: Tarde's monadology had triggered an interest in exploring objects as relational assemblages that eventually led me to the black cap; Vicente and Belén, in turn, deployed a rather monadological strategy in their account of its fabrication, which I set out to reproduce in my writing. I will return to the important question of whose ontology we talk about when we talk about monadology in the conclusion.

Secondly, removing quotation marks and dialogue lines highlighted the constructed nature of the text. The fragment above is not the transcription of a taped fieldwork interview; it is a re-construction of notes and recollections of several conversations, which I assembled and gave to Vicente and Belén to read and comment. Although the 'style' was solely my 
choice, the production of the text involved discussions in which the anonymity of the sensible elements was decided, my inaccuracies corrected, further detail provided, and the overall tone and direction of the narrative agreed. However limited our collaboration was, I think it points at an important methodological strategy and a logical consequence of the commitment to adopt the monad's point of view as opposed to an external one. Vicente and Belén acted as the spokesmen for the black cap, as it were; it was only coherent with the principles of monadic ethnography outline above to enter a dialogue with them.

Thirdly and very briefly, deploying a dialogic format was also a matter of interpellation: I wanted to put the reader in the position of the attentive listener that I had occupied during fieldwork.

The significance of these three gestures can probably only be gasped by briefly considering what not trying to engage with the monad from within would look like. The black cap story could have easily been framed as an example of the global post-Fordist transformation of the car industry which started in the late seventies. I could have provided a general description of such transformation as discussed in the specialist literature and then use fragments of my fieldwork to illustrate how it was experienced locally in the context of my study. This would not only reduce the actors' own theory of the reality they inhabit to mere side evidence, but also betray the fundamental monadological insight that the key to understanding the post-Fordist transformation lies in the small, in the myriad actions of its tiny components.

I would like to conclude this section by making clear that I am not arguing that dialogic writing is monadic ethnography's only or even preferred formal strategy. Far from it. My intention was simply to make explicit the choices I made in this particular instance of monadic description, as a result of trying to accommodate the object and the situation I was 
studying. I would not want to prevent the development of other forms of monadic ethnography by setting out formal guidelines.

\section{Conclusion: ontology, monadology, ethnography}

This article has explored the shape ethnography may take if one was to accept Gabriel Tarde's bold monadological hypothesis, namely that 'everything is a society'. For Tarde (and later on for Latour), 'society' and 'social' describe a universal form of association between heterogeneous elements, rather than a specific human aggregate. The resulting relational assemblages, or 'monads', are characterised by their infinitesimal complexity, irreducible heterogeneity, their openness and avidity toward other monads, and their chronically unstable condition. Tarde's monadology is based on the primacy of difference over identity, the interest in relations of possession or "having" rather than a concern over "being", and the centrality of hegemony (both within and between monads) in the conceptualisation of relationality. This particular combination of claims we have come to associate with Deleuzian- and ANT-inspired perspectives is, in my opinion, one of the reasons why the experiment of (re)thinking ethnography through Tarde's monadology is worth considering: as I have attempted to show in the previous sections, compared to some versions of ANT, monadic ethnography places a greater emphasis on relations of power and temporal dynamics; compared to some appropriations of Deleuzian theory, it is less speculative and more committed to fieldwork, to making sense of these assemblages from within, to 'following the actors'. Monadic ethnography may be in a position to balance out Deleuzian and Latourian readings of Tarde and negotiate a tricky yet productive in-betweenness.

Inasmuch as Tarde's monadology constitutes a strong ontological affirmation with regards to the make-up of the world, it may be productive to relate the project of a monadic ethnography to recent debates around the so-called 'ontological turn' in the social sciences - 
particularly within anthropology and Science and Technology Studies (STS). After all, the usefulness, appropriateness and politics of this growing interest in metaphysical questions in the context of social research cannot be taken for granted. Although a full account of this ongoing debate is outside the scope of this conclusion, it may be useful to briefly revisit some key positions within it. ${ }^{13}$

In anthropology, the question of ontology arises out of the perennial challenge of appropriately attending to systems of thought and theories which are other to ours, perhaps even incompatible. For Eduardo Viveiros de Castro, one of the early proponents of a becoming-ontology for the discipline,

the language of ontology is important for one specific and, let's say, tactical reason. It acts as a countermeasure to a derealizing trick frequently played against the native's thinking, which turns this thought into a kind of sustained phantasy, by reducing it to the dimensions of a form of knowledge or representation, that is, to an "epistemology" or a "worldview" (2003: 18).

The need to 'take seriously' the ontologies of the peoples one studies, that is, not as 'worldviews' but as 'worlds that are viewed', not as 'opinions' but as 'objectively experienced worlds', is at the basis of Viveiros de Castro’s $(2010 ; 2011)$ groundbreaking work on Amerindian perspectivism - an ontology he defines as 'perpendicular' and incommensurable to ours. Whereas Western ontology is based on the assumption that only one world/nature exists, which can however be interpreted or represented in many different ways (mono-naturalism, multiculturalism), perspectivism inverts this and establishes that there is one culture (shared among humans, spirits, animals and some plants) and many natures (mono-culturalism, multinaturalism). All entities see ('represent') the world in the same way, through the same categories ('food', 'home', etc.) but the world they see is different (blood for us, beer for jaguars; mud for us, ceremonial palace for tapirs). The 
importance of encountering this radically other ontology for Viveiros de Castro lies in its capacity to unsettle Western ontology, in particular its self-perceived superiority. By acknowledging the existence of alternative ontologies and engaging with them as proper metaphysical systems, anthropology - argues Viveiros de Castro - may finally be in a position to close its 'karmic cycle' and take on its new mission as the 'theory-practice of the permanent decolonisation of thought' (2010: 14) or, in other words, to become 'the science of the ontological self-determination of the world's peoples' (2003:18).

In sharp contrast, Phillipe Descola's work (2013) has engaged with the multiplicity of ontologies found in ethnographic studies as a problem of classification, and consequently developed a taxonomy based on how similarities and differences between humans and nonhumans are established across two distinct dimensions, 'interiority' and 'physicality'. Western ontology, which he calls 'naturalism', distinguishes humans from non-humans based on their internal difference, namely that only humans have a soul, consciousness, subjectivity and language. This ontology, dominant in the West since the $17^{\text {th }}$ Century, co-exists with three others: 'animism', 'totemism' and 'analogism'. For Descola, perspectivism is a particular 'type' of animism, where the distinction between humans and non-humans is based on their physicality, i.e. their physiological, perceptual and sensory-motor features. In short, in the work of Descola, the language ontology is an instrument for developing a 'relativist universalism' in anthropology - rather than, as Viveiros de Castro argued, a 'bomb' in the discipline's headquarters (see Latour, 2009 for a review of a debate between the two).

Yet another distinguishable form of engagement with ontology has been articulated by STS scholars. In a recent review of the 'ontological turn' in their field, Woolgar and Lezaún (2013) argue that while the 'turn' may indeed be seen as a move away from epistemology ('the object of inquiry is the very existence or being of entities, not merely the modes of knowing pre-existing entities'), this distinction has rarely been stable within STS, a 
perspective whose main concern is the analysis of how things come to be what they are, how objects and subjects are enacted and performed - in other words, 'how in practice, and in detail, particular ontologies are achieved'. Rather than committing to a particular ontology or 'theory of what there is',

our field's current curiosity about ontologies and their enactment is best understood as a way of extending its idiosyncratic critical sensibility - an appreciation of fluidity in seemingly stable entities, a recognition of difference beyond claims to singularity (and vice versa), a reluctance to take the world at face value - to the realm of the ready-made, to the world of those entities whose being might seem most unproblematic and ordinary. (2013: 336)

Where, then, stands monadic ethnography in all this? In my opinion, it represents a fourth mode of engagement with ontology, different from the three above and yet with selective affinities to all of them. This is because the monadology it is founded upon is both an ontology in itself (a theory of the make-up of reality based on monads and their relations) and a method for studying the monads' own ontologies. Tarde's monadology is therefore both an alternative to hegemonic naturalism (another ontology), and 'a way of making sense of a world woven from multiple ontologies' (Lorenc, p.c.) (a privileged route onto other ontologies). At the same time, Tarde's definition of monads as more or less fragile achievements implies a sustained interested in how they come to be, how they attain and maintain their ontological status. In his afterword to $M S$, Theo Lorenc develops the idea that Tarde's monadology implies a continuity between the ontological activity of the researcher and that of her objects:

the scientific or metaphysical theories we develop to explain reality would not be foreign to the elements, but on the contrary, would be profoundly continuous with the cosmic plans which form their own most intimate reality. Each element has, and in some sense is, an ontological theory of its own. 
Thus, Tardean metaphysics could be described as an ontology of ontologies: the universe is woven from the theorizing activity of its innumerable elements. (Lorenc, 2012: 92)

With this fractal scheme of self-similarity, Tarde elegantly addresses the ontological duplicity inherent to his argument. When it comes to doing ethnography, I would argue this duplicity is not so much a problem as a basic fieldwork condition: the people we work with also have their theories about the make-up of the world, and the relationship between theirs and ours is an empirical matter. In this article, an instance of remarkable isomorphism was presented but it is not hard to imagine scenarios of conflict, incommensurability or plain misunderstanding ${ }^{14}$.

Faced with a similar predicament, Henare et al. (2007) argued that 'hosting' alternative cosmologies does not necessarily mean replacing the old 'episteme of all epistemes' with a totalising 'ontology of all ontologies', but rather 'recuperat[ing] a facility [for concept production] informants may already have' and developing a methodology that might generate a 'multiplicity of theories' (2007: 16). This approach in turn echoes Latour's argument that ANT analysts should only possess an infra-language "whose role is simply to help them become attentive to the actors' own fully developed meta-language, a reflexive account of what they are saying' (2005: 49) - a move that as he acknowledges can be considered a revitalisation of ethnomethodology's programme: the study of the procedures by which society is produced by its members, and the theories they use to make sense of it (Garfinkel, 1967).

With regards to monadic ethnography, I would not be disappointed if the engagement with ontology translates into a minimal and rather humble aspiration: to become a form of research that, starting from a monadological understanding of reality, is open to engaging with the monads' performative power at all levels, including their theoretical and ontological work. Monadic ethnography may then become a battleground for the competition between 
theories, or a version (or a variation) of the monads' own theorising work. On occasion, it may become a vehicle for the transformation - perhaps even the possession - of our conceptualisations by those of the monads. In any case, an ethnographic approach based on the respect towards and attentiveness to the actors' own theories seems to me a valuable first step for this newly born creature; it carries with it an invitation to devise forms of theoretical collaboration and co-production with the people we work with and a call for an ethnographic practice which is seen, at its core, as an inventive activity, a machine for distributing new ideas, concepts, theories, beings.

\section{References}

Alliez É (2004) The Difference and Repetition of Gabriel Tarde. Distinktion: Scandinavian Journal of Social Theory, 5(2): 49-54.

Bakhtin MM (1981) The Dialogic Imagination: Four Essays. Austin: University of Texas Press.

Barry A (2010) Tarde's method: between statistics and experimentation. In: Candea M (ed.) The Social After

Gabriel Tarde: Debates and Assessments. London and New York: Routledge, pp. 177-190.

Bergson H (1962) Matter and memory. London: G. Allen \& Co.

Born G (2010) On Tardean relations: temporality and ethnography. In: Candea M (ed.) The Social After Gabriel Tarde: Debates and Assessments. London and New York: Routledge, pp. 230-247.

Candea M (ed.) (2010a) The Social After Gabriel Tarde. London and New York: Routledge.

Candea M (2010b) Revisiting Tarde's House. In Candea M (ed.) The Social After Gabriel Tarde. London and New York: Routledge, pp. 1-23.

Candea M and Alcayna-Stevens L (2012) Internal Others: Ethnographies of Naturalism. Cambridge Anthropology, 30(2): 36-47.

Carrithers M et al. (2010) Ontology Is Just Another Word for Culture. Critique of Anthropology, 30(2): 152 200. 
Clifford J and Marcus GE (1986) Writing culture: the poetics and politics of ethnography. Berkeley: University of California Press.

Debaise D (2008) The Dynamics of Possession: an introduction to the Sociology of Gabriel Tarde. In D.

Skribna, ed. Mind that Abides. Panpsychism in the new millenium. Amsterdam: John Benjamins, pp. 1-13.

DeLanda M (2006) A New Philosophy of Society: Assemblage Theory and Social Complexity. London:

Continuum.

Deleuze G (1988) Bergsonism. New York: Zone Books.

Deleuze G (1994) Difference and repetition. New York: Columbia University Press.

Deleuze G (2006) The fold: Leibniz and the Baroque. London and New York: Continuum.

Deleuze G (2006) Foucault. London and New York: Continuum.

Deleuze G and Guattari F (1989) A thousand plateaus: Capitalism and schizophrenia. Minneapolis: University of Minnesota Press.

Descola P (2013) Beyond Nature and Culture. Chicago: University of Chicago Press.

Didier E (2010) Gabriel Tarde and statistical movement. In: Candea M (ed.) The Social After Gabriel Tarde: Debates and Assessments. London and New York: Routledge, pp. 163-176.

Durkheim É (1982) The rules of sociological method. New York: Free Press.

Garfinkel H (1967) Studies in Ethnomethodology. New York: Prentice Hall.

Haraway D (1988) Situated Knowledges: The Science Question in Feminism and the Privilege of Partial Perspective. Feminist Studies, 14(3): 575-599.

Harman G (2009) Prince of networks: Bruno Latour and metaphysics. Melbourne: Re-press.

Henare A, Holbraad M and Wastell S (2007) Introduction: thinking through things. In: Henare A, Holbraad M and Wastell S (eds.) Thinking Through Things: Theorising Artefacts Ethnographically. London and New York: Routledge, pp. 1-31.

Jensen CB and Morita A (2012) Anthropology as critique of reality: A Japanese turn. Hau: Journal of Ethnographic Theory, 2(2): 358-70.

Kwa C (2002) Romantic and baroque conceptions of complex wholes in the sciences. In: Law J and Mol A (eds) Complexities: social studies of knowledge practices. Durham: Duke University Press, pp. 23-52. Latour B (2002) Gabriel Tarde and the End of the Social. In: Joyce P (ed.) The Social in Question. New Bearings in History and the Social Sciences. London and New York: Routledge, pp. 117-132. 
Latour B (2005) Reassembling the social: an introduction to actor-network-theory. Oxford and New York:

Oxford University Press.

Latour B (2010) Tarde's idea of quantification. In Candea M (ed.) The Social After Gabriel Tarde: Debates and Assessments. London and New York: Routledge, pp. 145-162.

Latour B (2009) Perspectivism: “Type” or “bomb”? Anthropology Today, 25(2): 1-2.

Latour B and Lepinay VA (2009) The Science of Passionate Interests: An Introduction to Gabriel Tarde's Economic Anthropology. Chicago: University of Chicago Press.

Latour B, Harman G and Erdely P (2011) The Prince and the Wolf: Latour and Harman at the LSE. Hants: Zero Books.

Latour B et al. (2012) 'The Whole is Always Smaller Than Its Parts' - A Digital Test of Gabriel Tarde’s Monads. The British Journal of Sociology, 63(4): 590-615.

Law J (2002) Objects and Spaces. Theory, Culture \& Society 19(5-6): 91-105.

Law J (2004) And if the global were small and noncoherent? Method, complexity, and the baroque.

Environment and Planning D: Society and Space, 22(1): 13-26.

Lazzarato M (2004) Les révolutions du capitalisme. Paris: Les Empêcheurs de Penser en Rond.

Leibniz GW (1898) The Monadology and other philosophical writings. London: Oxford University Press.

Laidlaw J and Heywood P (2013) One More Turn and You're There. Anthropology of This Century 7. Availble at: $<$ http://aotcpress.com/articles/turn/>

Loemker LE (2006) Monad and Monadology. In Borchert DM (ed) Encyclopedia of philosophy - Volume 6.

Detroit and London: Macmillan Reference, pp. 324-7.

López D and Sánchez-Criado T (2006) La recuperación de la figura de Gabriel Tarde: La 'neomonadología’ como fundación alternativa del pensamiento psicosocial. Revista de Historia de la Psicología, 27(2-3).

Lorenc T (2012) Afterword: Tarde's pansocial ontology. In: Tarde G Monadology and Sociology. Melbourne: Re-press, pp. 73-95.

Lubek I (1981) Histoire des psychologies sociales perdues. Le cas de Gabriel Tarde. Revue française de Sociologie, 22(3): 361-395.

Mucchielli L (2000) Tardomania? Réflexions sur les usages contemporains de Tarde. Revue d'Histoire des Sciences Humaines, 3: 161-184.

Pedersen MA (2012) Common Nonsense: A Review of Certain Recent Reviews of the 'Ontological Turn.' Anthropology of This Century 5. Available at $<$ http://aotcpress.com/articles/common_nonsense/> 
Sampson TD (2012) Virality: Contagion Theory in the Age of Networks. Minneapolis: University of Minnesota Press.

Spencer H (1906) The principles of sociology. New York: D. Appleton.

Tarde G (2000) Social Laws: An Outline of Sociology. Kitchener: Batoche Books.

Tarde G (2009) The Laws of Imitation. BiblioLife, LLC.

Tarde G (2012) Monadology and Sociology. Melbourne: Re-press.

Van Ginneken J (1992) Crowds, Psychology \& Politics, 1871-1899. Cambridge: Cambridge University Press.

Viana Vargas E (1998). Multiplicando os agentes do mundo: Gabriel Tarde e a sociologia infinitesimal. Revista Brasileira de Ciências Sociais, 19(55): 172-176.

Viana Vargas E (2010) Tarde on drugs, or measures against Suicide. In: Candea M (ed.) The Social After

Gabriel Tarde: Debates and Assessments. London and New York: Routledge, pp. 208-229

Viana Vargas E et al. (2008) The debate between Tarde and Durkheim. Environment and Planning D: Society and Space, 26(5): 761-777.

Viveiros de Castro E (2003) And. Manchester Papers in Social Anthropology 7. Available at: $<\mathrm{http}$ ://nansi.abaetenet.net/abaetextos/anthropology-and-science-e-viveiros-de-castro>

Viveiros de Castro E (2010) Métaphysiques cannibales: lignes d'anthropologie post-structurale. Paris: Presses Universitaires de France.

Viveiros de Castro E (2011) Zeno and the Art of Anthropology: Of Lies, Beliefs, Paradoxes, and Other Truths. Common Knowledge, 17(1): 128-145.

Viveiros de Castro E, Pedersen, MA and Holbraad M (2014) The Politics of Ontology: Anthropological Positions. Fieldsights - Theorizing the Contemporary, Cultural Anthropology Online, January 13, 2014. Available at: $<$ http://culanth.org/fieldsights/462-the-politics-of-ontology-anthropological-positions $>$ Weiss P (2005) The Aesthetics of Resistance. Durham: Duke University Press.

Woolgar S and Lezaún J (2013) The Wrong Bin Bag: A Turn to Ontology in Science and Technology Studies? Social Studies of Science, 43(3): 321-40.

1 A video recording of the debate, featuring Bruno Latour as Gabriel Tarde and Bruno Karsenti as Émile Durkheim can be found at: <http://www.bruno-latour.fr/node/434>

2 Tarde/Durkheim: Trajectories of the Social, at the University of Cambridge on 14-15 March 2008

3 Revue d'Histoire des Sciences Humaines, no. 3, 2000; Multitudes, no. 7, 2001; and Economy and Society, vol. 36, no. 4, 2007. 
4 See Candea (2010b) for an excellent overview of Tarde's work written with an anthropological sensibility. The recuperation of Tarde within social psychology is also remarkable and offers an alternative path into his ideas (see López and Sánchez-Criado, 2006; Lubek, 1981; Van Ginneken, 1992).

5 All the names of individuals and businesses have been anonymised, with the exception of Iracheta's family. When negotiating the publication of the text, and on the face of their disappearance as a family business, they choose to appear under their real names as an act of memory.

6 I thank Theo Lorenc for this formulation.

7 The parallels with Foucault's 'microphysics of power' are evident, and were already pointed out by Deleuze (2006).

8 This tentative vocabulary, developed in dialogue with Theo Lorenc, is an antidote to metaphors of 'flatness' routinely used to refer to relational ontologies, and which in our opinion betray the vertiginous verticality of Tarde's ontology.

${ }^{9}$ See Harman (2009) on the difficulty the concept of 'actor-network' has on this issue.

10 It falls outside the scope of this text to explore the relationship between Tarde's monads and the work of his successor as Chair of Philosophy at the College de France, Henri Bergson. Bergson's (1962) notion of the virtual coexistence of several times in a single plane is here particularly relevant (see also Deleuze 1988). 11 Granted, the question of finding an appropriate formal strategy for our ethnographic tales is not specific to monadic ethnography, and ever since the publication of Writing Culture (Clifford and Marcus, 1986) discussions around the literary grounds of ethnographic strategies of representation are commonplace. I have been inevitably influenced by these debates, even though I read anthropology in context of active rejection of the discipline's 'post-modern drift'.

${ }^{12}$ This epic novel, told from the perspective of a nameless young German worker, unfolds between 1937 and 1945 and narrates a collective experience of war and militancy in a journey through the rise of Nazism, the Spanish Civil War, and exile and underground resistance in France and Sweden. It was its form that I thought was relevant to a monadic approach to writing: the book consists of extremely long blocks of text, without quotation marks, in which a plurality of voices, temporalities and spaces are engaged in dialogic tension, withour ever succumbing to dialectical resolution.

13 For an excellent introduction to the 'turn', see Candea and Alcayna-Stevens (2012); Carrithers et al. (2010); Jensen and Morita (2012). 
${ }^{14}$ On the 'slippage' - or contradictions - produced by the different uses of ontology as 'essence' vs 'theory', see the debate between Pedersen (2012) and Laidlow and Heywood (2013). 